\title{
Effect of organic peroxides on the morphological, thermal and tensile properties of EVA-organoclay nanocomposites
}

\author{
S. B. Mishra, A. S. Luyt* \\ Department of Chemistry, University of the Free State (Qwaqwa Campus), Private Bag X13, Phuthaditjhaba, 9866, \\ South Africa
}

Received 26 December 2007; accepted in revised form 25 February 2008

\begin{abstract}
Nanocomposites were prepared using an ethylene vinyl acetate copolymer (EVA) and organically modified Cloisite ${ }^{\circledR}$ 93A clay in the absence and presence of dicumyl peroxide (DCP) and dibenzyl peroxide (DBP) as cross-linking agents. The results clearly show differences in the EVA-clay morphology of nanocomposites prepared in the absence of organic peroxides, and of those prepared in the presence of respectively DCP and DBP. It seems as if DCP may initiate grafting between the polymer and the clay, which results in an exfoliated morphology. The presence of clay seems to inhibit the initiation of EVA crosslinking by the DBP free radicals. These free radicals probably initiate hydroxylated edge-edge interaction between the clay layers, which gives rise to a flocculated morphology and reduced polymer-clay interaction. There is a good correlation between these morphologies and the thermal stabilities and total crystallinities of the nanocomposites. Clay incorporation and peroxide treatment did not significantly change the tensile properties.
\end{abstract}

Keywords: nanocomposites, EVA, morphology, thermal properties, tensile properties

\section{Introduction}

Organic-inorganic hybrids based on layered inorganic compounds, such as clays, and organic polymers have been studied because of exceptional properties like increased modulus [1-3], reduced gas permeability [4, 5], and enhanced thermal stability $[6,7]$. Dispersion of the silicate particles in the polymer matrix is improved by replacing the metal cations with ions bearing an aliphatic chain for compatibilizing the silicate. This compatibilization enhances its interaction with the polymer by enlarging the interlayer, and the compatibilized clay is known as an organoclay. In intercalated nanocomposites the penetration of the polymer matrix into the layered silicate occurs in a crystallographically regular fashion, regardless of the clay to polymer ratio [8]. In these nanocomposites the clay platelets are normally interlayered by a few molecular layers of polymer. Hydroxylated edgeedge interaction of silicate layers results in flocculated nanocomposites, which are similar in nature to intercalated nanocomposites [9].

The exchange capacity of the clay, the polarity of the reaction medium and the chemical nature of the interlayer cations (e.g. onium ions) are a few factors that control whether a particular organoclay hybrid can be synthesized as an intercalated or exfoliated structure. Since clay nanocomposites are able to produce dramatic improvements in a variety of properties, it is important to understand the factors that affect delamination of the clay. In exfoliated nanocomposites, individual clay layers are separated in a continuous polymer matrix by an average distance that depends on clay loading. Usually the clay content of an exfoliated nanocomposite is much lower than that of intercalated nano- 
composites [9]. The formation of these structures is mainly determined by the preparation methods of the nanocomposites and by the characteristics of the monomer or polymer and clay. For melt blending, the polarity of the chains of the polymer and the basal spacing of the clay are important for the structure of these nanocomposites.

It has been reported [10] that a low (10\%) amount of silicate added to the polymer is capable of dramatically reducing the influence of oxygen during thermo-oxidation, independent of whether the morphology is intercalated or exfoliated. Acid catalyzed deacetylation is, however, mostly observed in nitrogen and more evident in exfoliated structures [11]. A non-ionic dispersing agent helps to exfoliate alkylammonium modified montmorillonite into polyethylene, thus enhancing the tensile and gas barrier properties of the polymer. Amphiphilic copolymers intercalate organo-modified tactoids, hence increasing the d-spacing and decreasing the attraction between the silicate layers. This facilitates the exfoliation of highly anisomeric layers that enhances the properties of nanocomposites [12].

In the present study, the effects of organic peroxides on the morphology, as well as thermal and tensile properties, of the nanocomposites have been investigated. For this, a fixed amount of organic peroxide was used. The composite samples were prepared by using melt blending followed by extrusion.

\section{Experimental}

\subsection{Materials}

Ethylene vinyl acetate copolymer (EVA) with 9\% vinyl acetate (VA) content was supplied by Plastamid, Elsies River, South Africa. The melting point of EVA was $95^{\circ} \mathrm{C}$, and the density $0.930 \mathrm{~g} \cdot \mathrm{cm}^{-3}$.

Cloisite $^{\circledR}$ 93A clay (hydrogenated tallow ammonium salts of Bentonite), supplied by Southern Clay Products, Texas, USA, was used as reinforcement. The as received clay particles were disk-like stacks of thin silicate layers, $1 \mathrm{~nm}$ thick and ranging in length from $100 \mathrm{~nm}$ to several micrometers. The specific gravity of the clay particles (stacks), according to the suppliers, is $1.6-1.8 \mathrm{~g} \cdot \mathrm{cm}^{-3}$.
Dicumyl peroxide (DCP) and dibenzyl peroxide (DBP), used as cross-linking agents, were obtained from Aldrich Chemicals (WI, USA).

\subsection{Preparation of nanocomposites}

The EVA and organoclay were dried in an oven at $80^{\circ} \mathrm{C}$ overnight. They were melt blended using a Brabender Plastograph (Brabender, Duisberg, Germany) $50 \mathrm{ml}$ mixer followed by extrusion using a Brabender Plastograph (Brabender, Duisburg, Germany) single screw extruder. 1, 2 and 3\% by weight of clay were mixed with EVA for respectively 20, 30 and $40 \mathrm{~min}$. at $130^{\circ} \mathrm{C}$ and 60 r.p.m. For peroxide cured samples, $1 \%$ DCP or DBP was added after the initial mixing, followed by 5 min. mixing under the same conditions. The samples were then extruded at a screw speed of 60 r.p.m. at $130^{\circ} \mathrm{C}$ to obtain films with an average thickness of $0.45 \pm 0.05 \mathrm{~mm}$ and an average width of $15 \pm 1 \mathrm{~mm}$.

\subsection{Gel content determination}

The gel content of the samples was determined using toluene as solvent. 1-2 $\mathrm{g}$ of each composite was wrapped in a stainless steel wire mesh (normal aperture $0.04 \mathrm{~mm}$, wire diameter $0.04 \mathrm{~mm}$ ) supplied by Meschcape Industries in Edenvale, South Africa, and refluxed in the solvent for 12 hours, after which it was dried in an oven at $80 \pm 5^{\circ} \mathrm{C}$, followed by drying in air overnight. The gel content was determined as shown by Equation (1):

$$
\begin{aligned}
& \text { Gel content }= \\
& \frac{\text { mass of gel after solvent extraction }}{\text { initial sample mass }} \cdot 100
\end{aligned}
$$

\subsection{X-ray diffraction analysis (XRD)}

The degree of intercalation or exfoliation was evaluated using X-ray diffractometry (XRD). X-ray diffraction patterns of the nanocomposite samples were obtained using a D8 Advance X-ray Diffractometer with $\mathrm{CuK}_{\alpha}$ radiation, $\lambda=1.5406 \AA$ (Bruker AXS Inc., Madison, WI, USA). Detector: Na-I scintillation counter with monochromator. The analyses were done in the reflection mode between $2 \theta=2$ and $10^{\circ}$. 


\subsection{Tensile testing}

A Hounsfield H5KS universal testing machine (Hounsfield, Redhill, England) was used to investigate the tensile strength, tensile modulus and elongation properties of the nanocomposites. Samples of $150 \mathrm{~mm} \times 15 \mathrm{~mm} \times 0.45 \mathrm{~mm}$ were cut for tensile testing. Samples with a gauge length of $50 \mathrm{~mm}$ were analyzed at a crosshead speed of $10 \mathrm{~mm} \cdot \mathrm{min}^{-1}$. A continuous load-deflection curve was obtained. The averages and standard deviations of 5 tests per sample are reported.

\subsection{Thermogravimetric analysis (TGA)}

Thermogravimetric analysis was performed in a Perkin Elmer TGA7 thermogravimetric analyser (Perkin Elmer, Wellesley, MA, U.S.A.). The sample mass was $6-8 \mathrm{mg}$. The analyses were carried out from 30 to $600^{\circ} \mathrm{C}$ at a heating rate of $10^{\circ} \mathrm{C} \cdot \mathrm{min}^{-1}$ under nitrogen atmosphere (flow rate $20 \mathrm{ml} \cdot \mathrm{min}^{-1}$ ).

\subsection{Differential scanning calorimetry (DSC)}

DSC analyses were performed in a Perkin Elmer DSC7 differential scanning calorimeter (Perkin Elmer, Wellesley, MA, U.S.A.). The analyses were carried out on 5-10 mg samples between 30 and $200^{\circ} \mathrm{C}$ at heating and cooling rates of $10^{\circ} \mathrm{C} \cdot \mathrm{min}^{-1}$ under nitrogen atmosphere (flow rate $20 \mathrm{ml} \cdot \mathrm{min}^{-1}$ ). The onset and peak temperatures of melting, as well as melting enthalpies, were obtained from the second heating cycle.

\subsection{Scanning electron microscopy (SEM)}

SEM analyses of the nanocomposites were performed using a JEOL WINSEM-6400 electron microscope (JEOL Ltd., Tokyo, Japan). The probe size was $114.98 \mathrm{~nm}$, the probe current $0.02 \mathrm{nA}$, the noise reduction $64 \mathrm{Fr}$ and the $\mathrm{AC}$ voltage $5.0 \mathrm{keV}$. The surfaces of the samples were coated with gold by an electrode deposition method to impart electrical conductivity before recording the SEM micrographs.

\subsection{SEM-EDX (energy dispersive $X$-ray diffraction)}

The SEM-EDX analyses were done in a Shimadzu SSX-550 scanning electron microscope (Shimadzu
Corporation, Kyoto, Japan) at an AC voltage of $15.00 \mathrm{kV}$ and a working distance of $17 \mathrm{~mm}$. SEMEDX pictures were taken from the same area as the SEM pictures.

\subsection{Transmission electron microscopy (TEM)}

The samples were prepared using cryo-ultramicrotomy. They were mounted on cryo-pins and frozen in liquid nitrogen. Sections were cut at $-100^{\circ} \mathrm{C}$ using a Reichert FCS (Leica, Vienna, Austria) attached to a Reichert Ultracut S Ultramicrotome. The sections (100-150 nm thick) were collected on copper grids and viewed in a LEO 912 Omega (Carl Zeiss NTS GmbH, Oberkochen, Germany) transmission electron microscope, with an energy filter, operating at $120 \mathrm{kV}$.

\section{Results and discussion}

The purpose of this work was to try and establish whether introduction of an organic peroxide to the molten polymer-clay mixture will influence clay delamination and dispersion in the polymer matrix. Such influence may be the result of grafting between the polymer and clay, or crosslinking of the polymer. Although it is known [1] that clay exfoliates better into higher vinyl acetate (VA) containing EVA, we used 9\% VA containing EVA so that any effect of the peroxide will not be overshadowed by a strong interaction between the EVA and clay modifier. Dicumyl peroxide (DCP) was used as crosslinking initiator at a temperature well below its optimum decomposition temperature ( $1 \mathrm{~h}$ halflife at $136^{\circ} \mathrm{C}$ ), while dibenzoyl peroxide (DBP) was used at a temperature above its optimum decomposition temperature $\left(1 \mathrm{~h}\right.$ half-life at $\left.91^{\circ} \mathrm{C}\right)$. Although the DCP may not have decomposed completely under the nanocomposite preparation conditions, there would have been enough decomposition to supply free radicals to the already mixed EVA/ organoclay nanocomposites.

The XRD spectra of all the investigated samples are shown in Figure 1 and the $2 \theta$ and associated $d$-spacing values for the clay (001) peaks are summarized in Table 1. Figure 1a compares the spectrum of the pure clay with those of the $1 \%$ clay containing composites prepared in the absence and presence of DCP and DBP. The clay shows a (001) 

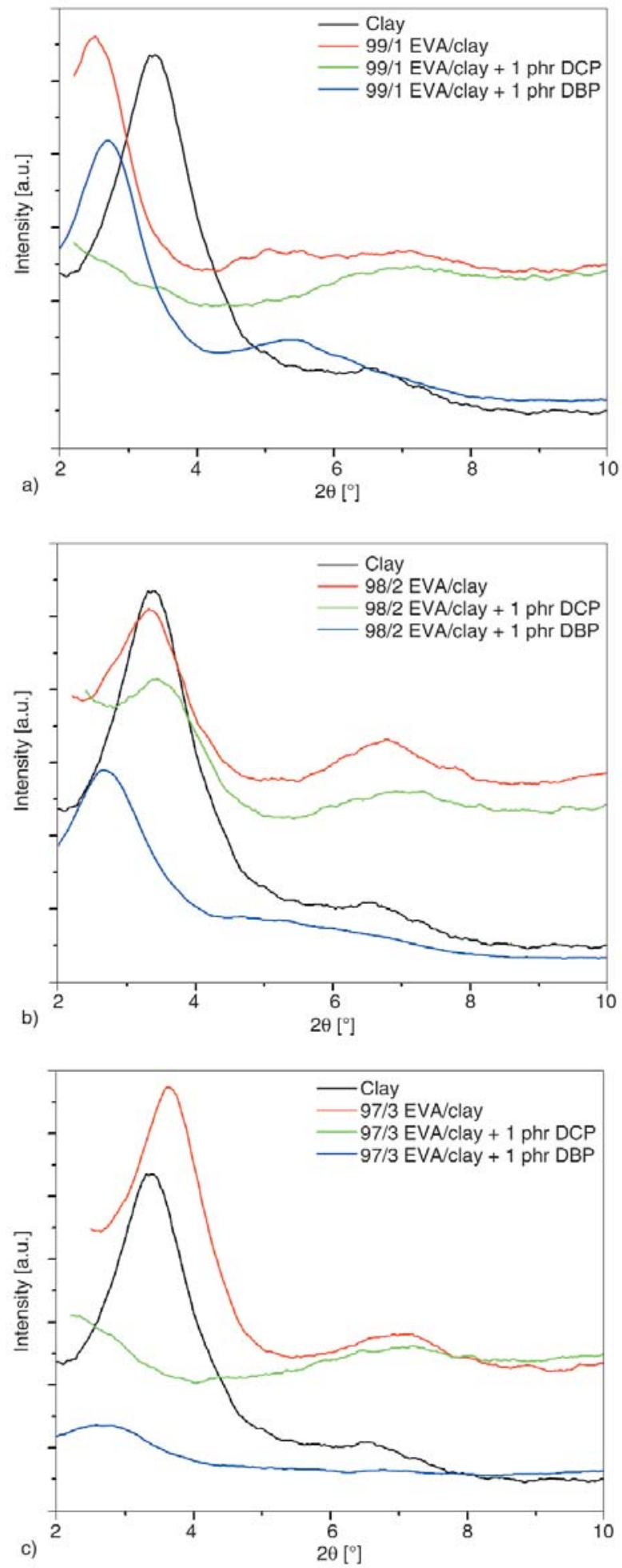

Figure 1. XRD spectra of EVA/clay (absence and presence of $1 \%$ peroxide) containing (a) $1 \%$ Cloisite 93A, (b) 2\% Cloisite 93A, and (c) $3 \%$ Cloisite 93A

diffraction peak at $2 \theta=3.4^{\circ}$ which corresponds to a $d$-spacing of $2.6 \mathrm{~nm}$, while the EVA/clay sample, containing $1 \%$ clay and prepared in the absence of an organic peroxide, shows possible intercalation
Table 1.2 2 and $d$-spacing values of the (001) diffraction peak of the clay in the different nanocomposites

\begin{tabular}{|l|c|c|}
\hline \multicolumn{1}{|c|}{ Sample } & $\mathbf{2 \theta}\left[{ }^{\circ}{ } \mathbf{c |}\right.$ & d-spacing $[\mathbf{n m}]$ \\
\hline Clay & 3.4 & 2.6 \\
\hline EVA/clay (1\%) & 2.4 & 3.7 \\
\hline EVA/clay (1\%)/DCP & no peak & - \\
\hline EVA/clay (1\%)/DBP & 2.7 & 3.3 \\
\hline EVA/clay (2\%) & 3.3 & 2.7 \\
\hline EVA/clay (2\%)/DCP & 3.4 & 2.6 \\
\hline EVA/clay (2\%)/DBP & 2.6 & 3.4 \\
\hline EVA/clay (3\%) & 3.6 & 2.5 \\
\hline EVA/clay (3\%)/DCP & no peak & - \\
\hline EVA/clay (3\%)/DBP & 2.6 & 3.4 \\
\hline
\end{tabular}

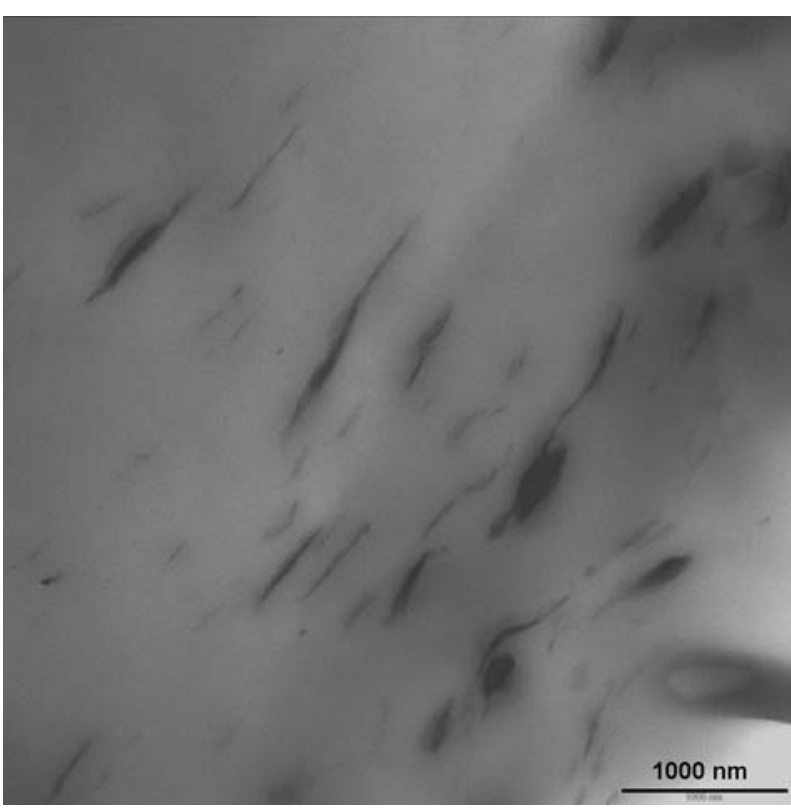

Figure 2. TEM image of a $3 \%$ clay containing sample prepared in the absence of peroxide

with an increase in d-spacing to $3.7 \mathrm{~nm}$. In the case of the samples containing 2\% (Figure $1 \mathrm{~b}$ ) and $3 \%$ (Figure 1c) clay there seems to be no intercalation or exfoliation of the clay in EVA. This was expected as a result of the known weak interaction between organoclay and EVA with low VA content. It is, however, possible that minimal intercalation also occurred in the case of the $1 \%$ clay containing sample, because it has been shown that XRD is not a very reliable technique for establishing clay intercalation/exfoliation at low clay contents [13]. This observation is supported by the TEM image in Figure 2 that show the clay particles with little evidence of intercalation and no exfoliation.

For the samples prepared in the presence of DCP there seems to be a much stronger interaction between the EVA and clay. The 1\% clay containing 
Table 2. Gel content values for samples prepared in the presence of DCP and DBP respectively (mass \% of clay initially mixed into sample was subtracted)

\begin{tabular}{|l|c|}
\hline \multicolumn{1}{|c|}{ Sample } & Gel content [\%] \\
\hline Pure EVA & 0.2 \\
\hline 99/1 w/w EVA/clay + 1 phr DCP & 0.4 \\
\hline 99/1 w/w EVA/clay + 1 phr DBP & 5.9 \\
\hline
\end{tabular}

samples show no (001) diffraction peaks (Figure 1a), indicating exfoliation into the EVA matrix. Gel content measurements on the samples show no gel formation and therefore no, or very little crosslinking, of EVA in the presence of DCP (Table 2). We assume that any available peroxide free radicals may have initiated some form of interaction between the EVA chains and the clay. A suggested mechanism will involve hydrogen abstraction from polymer chains and clay $-\mathrm{OH}$ groups by peroxide free radicals, followed by grafting between polymer chains and clay platelets. In the case of the samples containing 2\% (Figure 1b) and 3\% (Figure 1c) clay there seems to be partial exfoliation (smaller (001) peaks), but no intercalation. The absence of intercalation supports the idea that the polymer interacts with the clay without penetrating the clay layers [14]. The absence of complete exfoliation is the result of increasing clay:DCP ratios, giving rise to reduced interaction between the EVA chains and the clay. Figure $3 \mathrm{a}$ shows good exfoliation of the DCP treated, $1 \%$

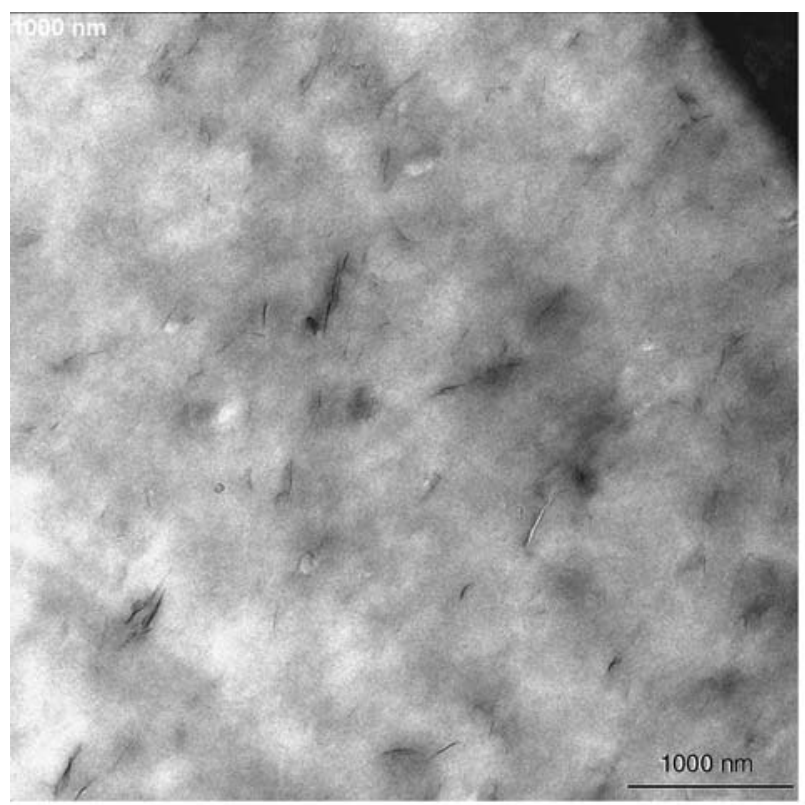

a) clay-containing samples, although some small tactoids are visible. Figure $3 b$ does not only show fairly good exfoliation of the clay in the polymer matrix, but also very obvious orientation of the clay platelets in the extrusion direction.

Nanocomposite samples prepared in the presence of DBP show completely different morphologies from those prepared in the presence of DCP (Figure 1). In this case a mixed morphology is clearly observed. The $2 \theta$ values of the (001) diffraction peaks are lower, while there is a development of a second peak at higher $2 \theta$ values. There are different views as to what may give rise to this additional (00l) diffraction peak. Sinha Ray and Okamoto [9] attribute it to flocculation of clay layers caused by hydroxilated edge-edge interaction, while Galimberti et al. [14] discuss the possibility that such a peak could appear under certain preparation conditions, and is not necessarily the result of flocculation. The TEM images in Figure 4 indicate a mixed morphology. It is not completely clear why the presence of DBP, which certainly was completely decomposed under the preparation conditions used, did not give rise to exfoliation as in the case of DCP treated samples. The gel content results (Table 2) show the formation of gel when DBP was introduced in the samples, but the extent of gelation is still much lower than expected. In this case there may have been stronger interactions between the polymer and the clay, but there was also polymer crosslinking and possibly hydroxylated edge-edge

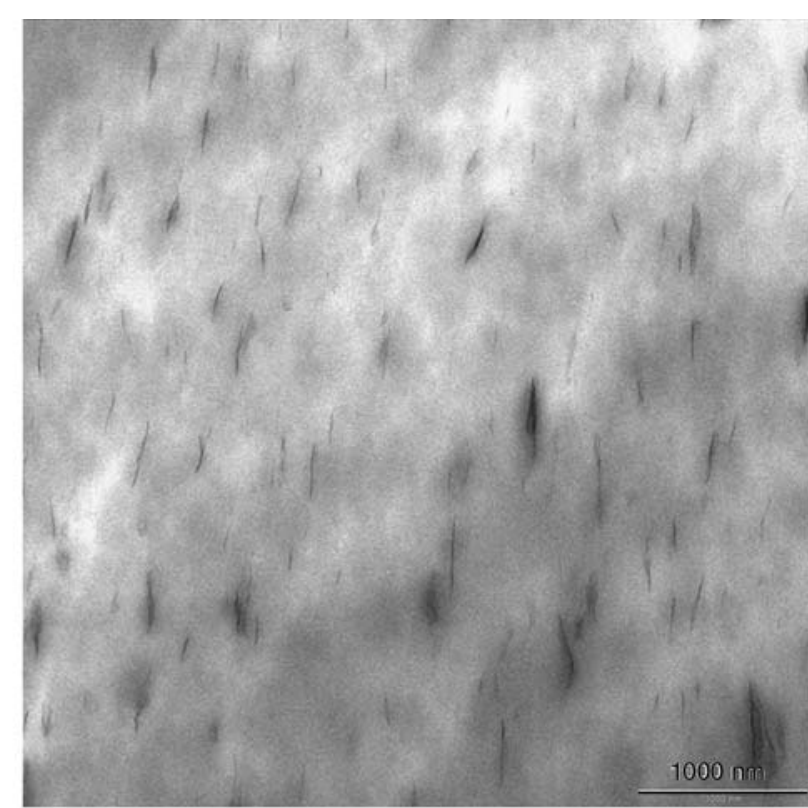

b)

Figure 3. TEM images of (a) $1 \%$ clay and (b) $3 \%$ clay containing samples prepared in the presence of DCP 


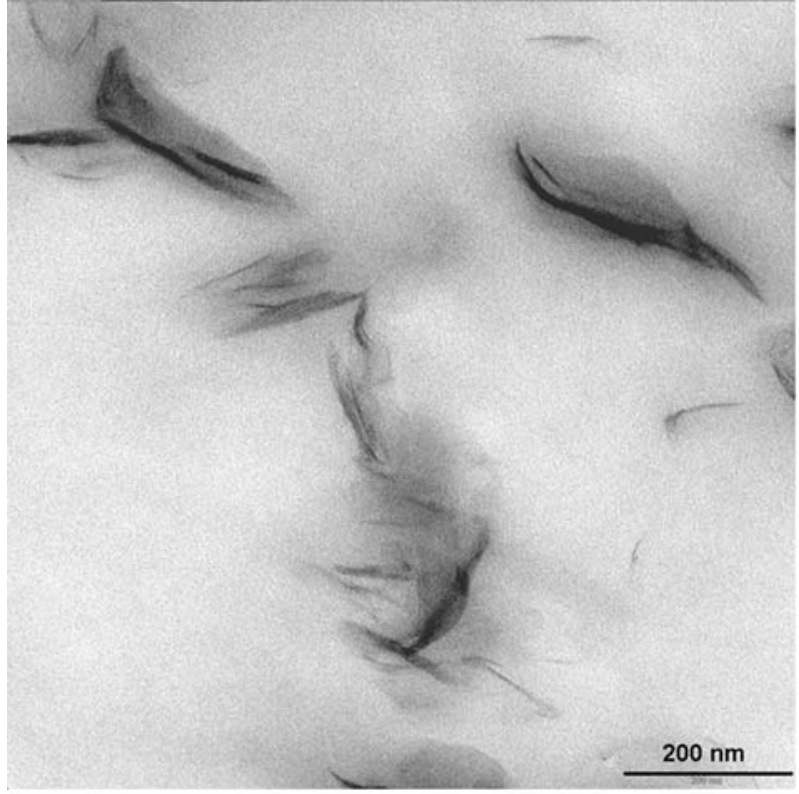

a)

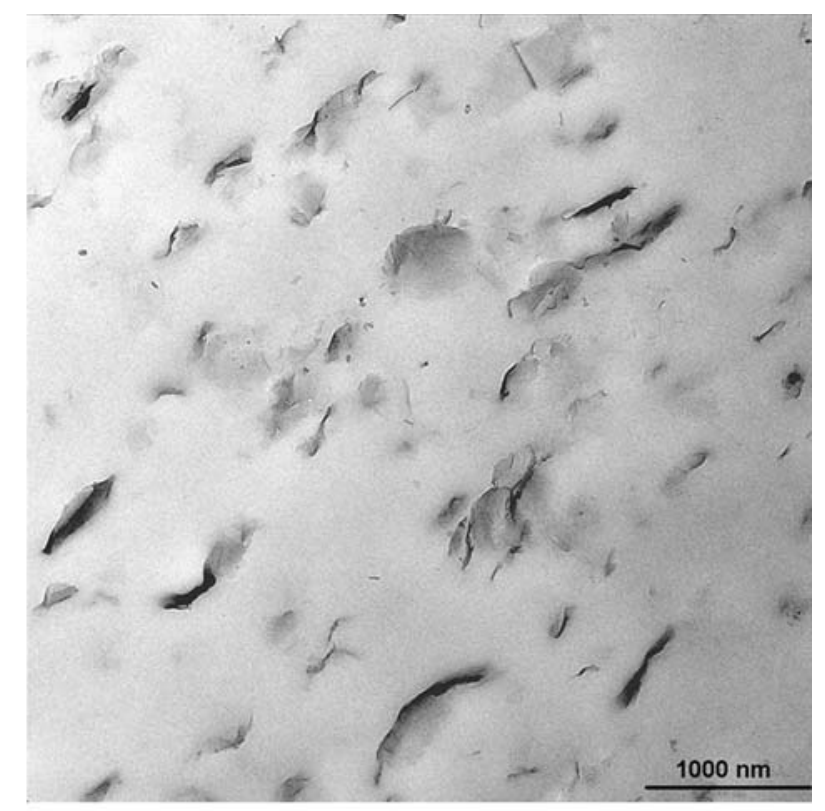

b)

Figure 4. TEM images of (a) $1 \%$ clay and (b) $3 \%$ clay samples prepared in the presence of DBP

interactions between the clay layers. A combination of these reactions and resulting interactions then gave rise to the observed mixed morphology.

SEM and SEM-EDX images of EVA/clay with DCP are shown in Figure 5. These images show regular leaflet patterns. The SEM-EDX image (Figure $5 b$ ), showing silica (in light grey) along the lines of the pattern, indicates a higher clay concentration on the edges of the pattern. We assume that this pattern is the result of some roughness on the surface of the die, combined with the shear forces of extrusion and the attraction forces between the matrix and the clay.

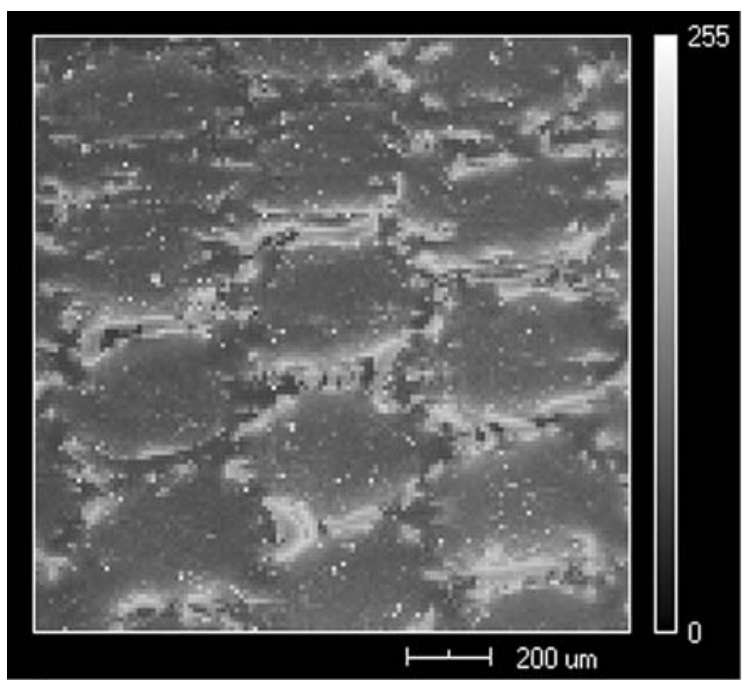

a)
The TGA curves (Figure 6) show a two-step degradation of the nanocomposites. The onset temperature of the first step was found to be in the range of $315-335^{\circ} \mathrm{C}$, which corresponds to the release of acetic acid. At temperatures above $380^{\circ} \mathrm{C}$, thermal degradation of the ethylene-co-acetylene main chain takes place [11]. The TGA curves clearly show that pure EVA is thermally more stable than any of the nanocomposites, whether prepared in the absence or presence of peroxide. The thermal decomposition of organo-modifier will generate strong acidic sites that will accelerate the deacetylation of EVA in the nanocomposites. These sites

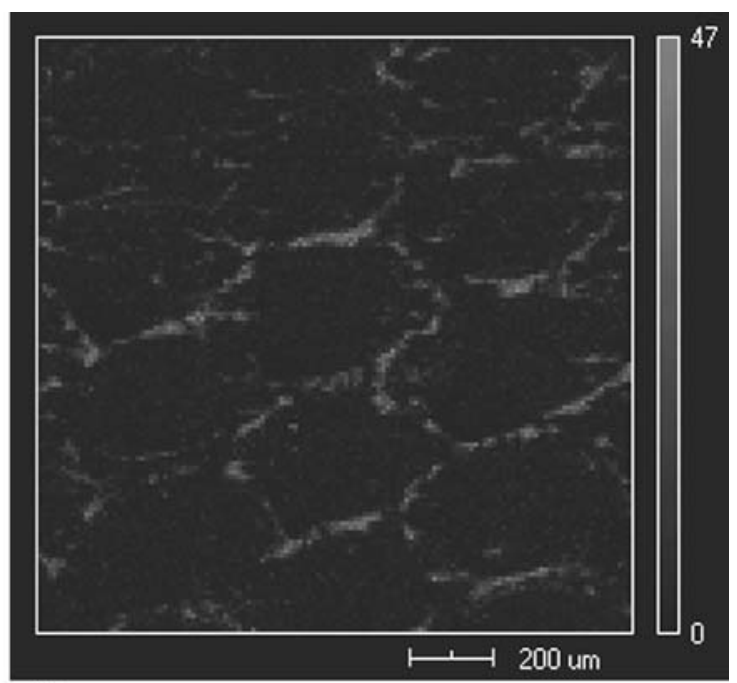

b)

Figure 5. (a) SEM and (b) SEM-EDX images of a 3\% clay containing sample prepared in the presence of DCP 

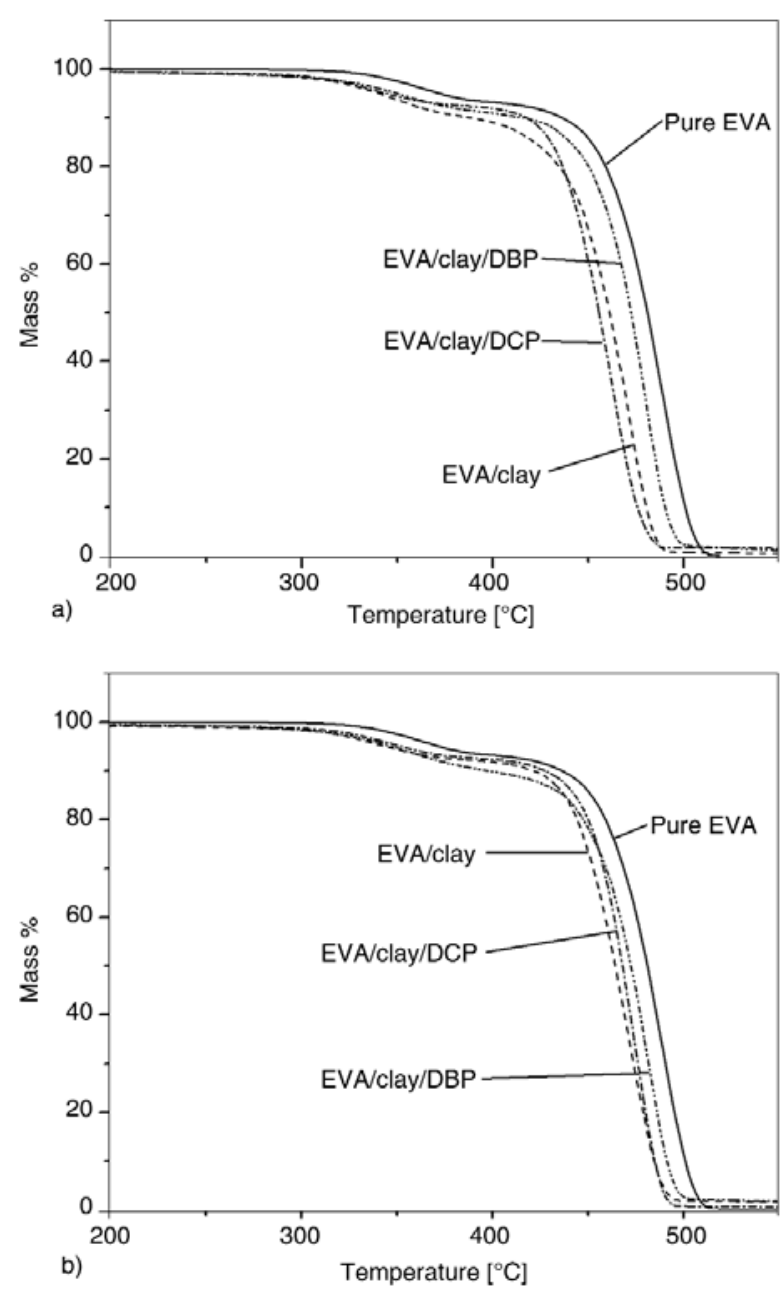

Figure 6. TGA curves of (a) EVA/Cloisite 93A (1\%) and (b) EVA/Cloisite 93A (3\%) prepared in the absence and in the presence of $1 \%$ peroxide

are active when there is intimate contact between the polymer and the silicate layers [8]. This is probably the reason why the exfoliated samples of the DCP treated nanocomposites were the least thermally stable. The DBP treated nanocomposites were observed to have a mixed morphology, including flocculation and the formation of tactoids. As a result the clay was not well dispersed within the polymer matrix, which reduced the influence of the acidic sites on the deacetylation of EVA. There was, however, no direct relationship between the thermal stability of the nanocomposites and the amount of clay.

Table 3 summarizes the peak temperatures of melting and crystallization, as well as the melting and crystallization enthalpies, of pure EVA and the nanocomposites. These values were obtained from the second heating and cooling cycles of the DSC analyses. The peak temperatures of melting and crystallization of EVA in the different samples show differences, but there is no trend or correlation with the observed morphology. The presence of clay, however, has an influence on the total crystallinity of the EVA matrix. When comparing the melting and crystallization enthalpies of pure EVA and EVA in the nanocomposites (Table 3), it is clear that the nanocomposites have 20-30\% lower enthalpy values than pure EVA. It is further clear that the samples prepared in the presence of DBP have higher enthalpy values than those prepared in the presence of DCP. There is a good correlation between the enthalpy (which is an indication of total crystallinity) and the extent of intercalation or exfoliation (as indicated by the XRD and TEM results). The presence of clay, whether non-dispersed, intercalated, flocculated or exfoliated, clearly reduces the EVA chain mobility, resulting in a lower total crystallinity. In the presence of DCP there is more exfoliation, resulting in a much larger EVA-clay interphase which gives rise to more reduced chain mobility and lower total crystallinity. The lower extent of exfoliation, as well as the presence of flocculation, of the clay layers

Table 3. Peak temperatures of melting and crystallization, as well as melting and crystallization enthalpies, of the different nanocomposites

\begin{tabular}{|l|c|c|c|c|}
\hline \multicolumn{1}{|c|}{ Sample } & $\mathbf{T}_{\mathbf{p}, \mathbf{m}}\left[{ }^{\circ} \mathbf{C}\right]$ & $\Delta \mathbf{H}_{\mathbf{m}}\left[\mathbf{J} \cdot \mathbf{g}^{-\mathbf{1}}\right]$ & $\left.\mathbf{T}_{\mathbf{p}, \mathbf{c}}{ }^{\circ} \mathbf{C}\right]$ & $\Delta \mathbf{H}_{\mathbf{c}} / \mathbf{J} \cdot \mathbf{g}^{-\mathbf{1}}$ \\
\hline Pure EVA & 95.8 & 57.2 & 81.3 & -65.4 \\
\hline EVA/ clay (1\%) & 95.7 & 46.9 & 78.5 & -45.3 \\
\hline EVA/ clay (1\%)/DCP & 94.2 & 40.7 & 78.6 & -34.6 \\
\hline EVA/ clay (1\%)/DBP & 93.7 & 46.4 & 79.1 & -48.6 \\
\hline EVA/clay (2\%) & 96.5 & 45.6 & 78.8 & -43.6 \\
\hline EVA/clay (2\%)/DCP & 93.7 & 40.2 & 76.9 & -44.8 \\
\hline EVA/clay (2\%)/DBP & 95.3 & 46.4 & 81.3 & -46.2 \\
\hline EVA/clay (3\%) & 96.5 & 44.2 & 79.9 & -37.9 \\
\hline EVA/clay (3\%)/DCP & 93.2 & 44.3 & 77.3 & -42.1 \\
\hline EVA/clay (3\%)/DBP & 95.2 & 47.2 & 81.3 & \\
\hline
\end{tabular}

$T_{p, m}$ - peak temperature of melting; $T_{p, c}$ - peak temperature of crystallization; $\Delta H_{m}$ - melting enthalpy; $\Delta H_{m}-$ crystallization enthalpy 
Table 4. Tensile properties of the different nanocomposites

\begin{tabular}{|l|c|c|}
\hline \multicolumn{1}{|c|}{ Sample } & $\sigma_{\mathbf{b}} \pm \mathbf{s} \sigma_{\mathbf{b}}[\mathbf{M P a}]$ & $\mathbf{E} \pm \mathbf{s E}[\mathbf{M P a}]$ \\
\hline Pure EVA & $6.5 \pm 1.5$ & $24.8 \pm 3.3$ \\
\hline EVA/clay (1\%) & $6.9 \pm 0.4$ & $29.2 \pm 1.9$ \\
\hline EVA/clay (1\%)/DCP & $7.3 \pm 1.6$ & $29.0 \pm 3.3$ \\
\hline EVA/clay (1\%)/DBP & $6.0 \pm 1.0$ & $25.4 \pm 2.8$ \\
\hline EVA/clay (2\%) & $6.6 \pm 0.2$ & $28.0 \pm 0.5$ \\
\hline EVA/clay (2\%)/DCP & $7.1 \pm 1.6$ & $33.7 \pm 4.7$ \\
\hline EVA/clay (2\%)/DBP & $6.5 \pm 0.4$ & $26.8 \pm 3.9$ \\
\hline EVA/clay (3\%) & $6.0 \pm 0.2$ & $25.4 \pm 2.3$ \\
\hline EVA/clay (3\%)/DCP & $6.1 \pm 0.5$ & $25.9 \pm 4.0$ \\
\hline EVA/clay (3\%)/DBP & $6.4 \pm 0.3$ & $24.0 \pm 0.7$ \\
\hline
\end{tabular}

$\sigma_{b}-$ stress at break; $E$ - Young's modulus

reduce the EVA-clay interphase and therefore have less influence on the polymer chain mobility. The total crystallinity of the DBP treated samples, as indicated by the melting or crystallization enthalpies, is therefore higher.

The tensile data are shown in Table 4. The tensile modulus of a polymeric material has been shown to improve when nanocomposites are formed with layered silicates [9]. This depends upon the nature of interaction between the polymer matrix and silicate layers. The tensile properties of the nanocomposites largely depend upon the amount and the nature of the filler present. In our case the presence of up to 3\% Cloisite 93A clay in EVA had little influence on both the tensile strength and modulus of the samples. This is in line with earlier observations $[15,16]$, where up to $3 \%$ Cloisite 15 A clay in the same EVA gave similar values for the tensile strength and modulus. Peroxide treatment also seemed to have little influence on these properties, although both the tensile strength and modulus are about $10-20 \%$ higher for the 1 and $2 \%$ clay containing samples prepared in the presence of DCP. These were also the only samples showing some degree of exfoliation.

\section{Conclusions}

The results discussed in this paper clearly show differences in the EVA-clay morphology of nanocomposites prepared in the absence of organic peroxides, and of those prepared in the presence of respectively DCP (which has a slow decomposition under the preparation conditions) and DBP (which should completely decompose under the preparation conditions). It seems as if DCP, under the preparation conditions, much more improves the polymer-clay interaction than DBP. The presence of clay also seems to inhibit the initiation of crosslinking by the DBP free radicals, probably because these free radicals initiates hydroxylated edge-edge interaction between the clay layers, which gives rise to a flocculated morphology and reduced polymer-clay interaction. There is a good correlation between these morphologies and the thermal stabilities of the nanocomposites, as studied through TGA, the total crystallinity, as seen from the DSC melting and crystallization enthalpies. There is, however, little difference between the modulus and tensile strength values of the different samples.

\section{Acknowledgements}

The National Research Foundation (GUN 2070099) and the University of the Free State in South Africa are acknowledged for financial support. Dr Remy Bucher from iThemba LABS in Somerset West, South Africa did the XRD analyses.

\section{References}

[1] Chaudhary D. S., Prasad R. Gupta R. K., Bhattacharya S. N.: Clay intercalation and influence on crystallinity of EVA-based clay nanocomposites. Thermochimica Acta, 433, 187-195 (2005).

[2] Ghosh A. K., Woo E. M.: Analyses of crystal forms in syndiotactic polystyrene intercalated with layered nano-clays. Polymer, 45, 4749-4759 (2004).

[3] Vaia R. A., Price G., Ruth P. N., Nguyen H. T., Lichtenhan J.: Polymer/layered silicate nanocomposites as high performance ablative materials. Applied Clay Science, 15, 67-92 (1999).

[4] Usuki A., Tukigase A., Kato M.: Preparation and properties of EPDM-clay hybrids. Polymer, 43, 2185 2189 (2002).

[5] Gilman J. W.: Flammability and thermal stability studies of polymer layered-silicate (clay) nanocomposites. Applied Clay Science, 15, 31-49 (1999).

[6] Zhang W., Chen D., Zhao Q., Fang Y.: Effects of different kinds of clay and different vinyl acetate content on the morphology and properties of EVA/clay nanocomposites. Polymer, 44, 7953-7961 (2003).

[7] Duquesne S., Jama C., Le Bras M. L., Delobel R., Recourt P., Gloaguen J. M.: Elaboration of EVA-nanoclay systems-characterization, thermal behaviour and fire performance. Composites Science and Technology, 63, 1141-1148 (2003).

[8] Zanneti M., Camino G., Thomann R., Mülhaupt R.: Synthesis and thermal behaviour of layered silicateEVA nanocomposites. Polymer, 42, 4501-4507 (2001). 
[9] Sinha Ray S., Okamoto M.: Polymer/layered silicate nanocomposites: A review from preparation to processing. Progress in Polymer Science, 28, 1539-1641 (2003).

[10] Riva A., Zanetti M., Braglia M., Camino G., Faliqui L.: Thermal degradation and rheological behaviour of EVA/montmorillonite nanocomposites. Polymer Degradation and Stability, 77, 299-304 (2002).

[11] Massa A., Scettri A., Contessa S., Bugatti V., Concilio S., Iannelli P.: New catalyst for the synthesis of poly(butylene terephthalate) with high thermo-oxidative stability. Journal of Applied Polymer Science, 104, 3071-3076 (2007).

[12] Zhang X., Guo F., Chen J., Wang G., Liu H.: Investigation of interfacial modification for flame retardant ethylene vinyl acetate copolymer/alumina trihydrate nanocomposites. Polymer Degradation and Stability, 87, 411-418 (2005).
[13] Százdi L., Ábrányi A., Pukánszky B. Jr., Vancso J. G., Pukánszky B.: Morphology characterization of PP/ clay nanocomposites across the length scales of the structural architecture. Macromolecular Materials and Engineering, 291, 858-868 (2006).

[14] Galimberti M., Lostritto A., Spatola A., Guerra G.: Clay delamination in hydrocarbon rubbers. Chemistry of Materials, 19, 2495-2499 (2007).

[15] Guduri B. R., Luyt A. S.: Effect of ethylene glycidyl methacrylate compatibilizer on the structure and mechanical properties of clay nanocomposites modified with ethylene vinyl acetate copolymer. Journal of Applied Polymer Science, 103, 4095-4101 (2007).

[16] Guduri B. R., Luyt A. S.: Comparison of the influence of different compatibilizers on the structure and properties of ethylene vinyl acetate copolymer/modified clay nanocomposites. Journal of Applied Polymer Science, 105, 3612-3617 (2007). 